\title{
AGENTES ETIOLÓGICOS DE DIARREA: BACTERIAS Y PARÁSITOS IMPORTANTES EN NIÑOS Y ADULTOS
}

\section{[ETIOLOGIC AGENTS OF DIARRHEA: BACTERIA AND PARASITES OF IMPORTANCE IN CHILDREN AND ADULTS]}

\author{
Rito Zerpa L. ${ }^{1}$
}

\begin{abstract}
En las siguientes microfotografías se presenta bacterias y parásitos importantes (no se incluye algunas bacterias enteropatógenas ni virus) que son agentes etiológicos de diarrea en pacientes inmunocompetentes e inmunocomprometidos, niños y adultos, en especial de Vibrio cholerae, causante de la epidemia de cólera en el Perú y otros países en la década de 1990 y que en la actualidad afecta a países como Haití, El Salvador y Venezuela.
\end{abstract}

Las imágenes especiales, algunas a más de 1000 aumentos, bi- $y$ tridimensionales, han sido obtenidas $\sin$

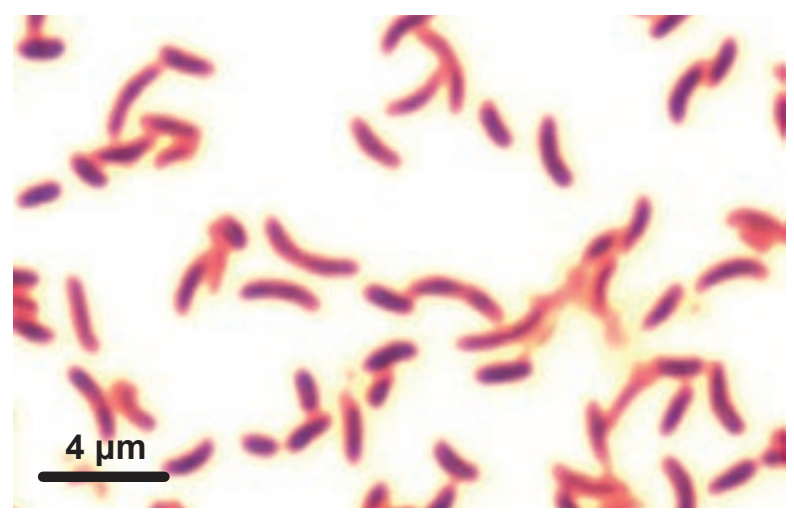

Figura 1. Vibrio cholerae, agente etiológico del cólera, en frotis de cultivo puro, con la tinción de Gram. Se observan bacilos curvados Gram negativos.

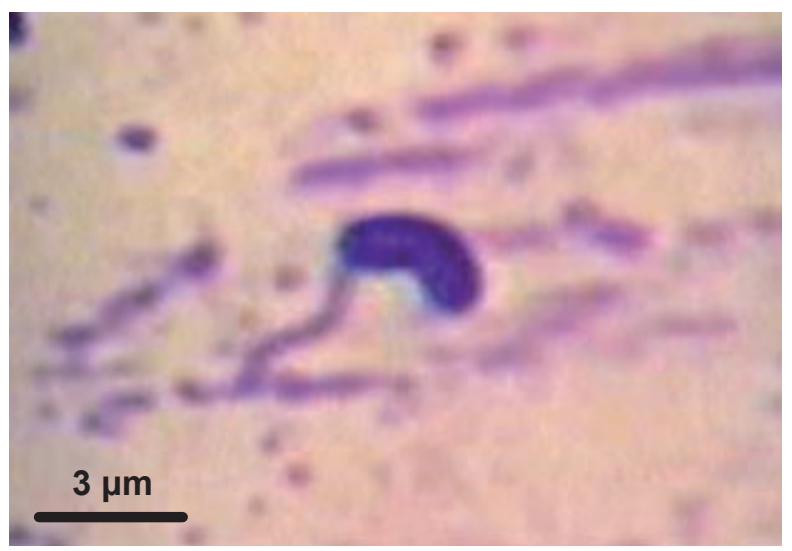

Figura 2. Vibrio cholerae, en frotis de cultivo puro, con la tinción de Kodaka para visualizar flagelos. Se observa al bacilo curvado con un flagelo polar. necesidad del microscopio electrónico de transmisión o de barrido (scanning); estos agentes etiológicos fueron hallados en muestras de pacientes con enfermedad diarreica, que acudieron para su atención al Instituto Nacional de Salud del Niño y al Instituto de Medicina Tropical Daniel A. Carrión (UNMSM).

Las imágenes pueden ser de utilidad para el diagnóstico microbiológico y parasitológico en el laboratorio clínico, en la docencia y en la investigación.

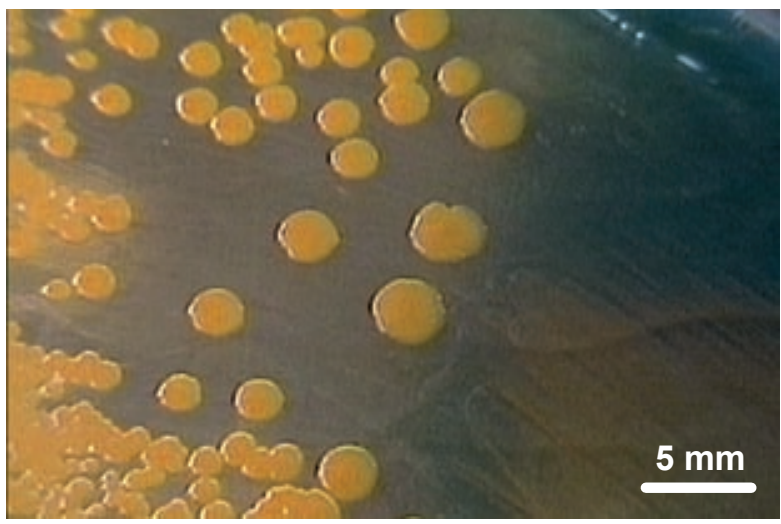

Figura 3. Vibrio cholerae, foto obtenida a partir de cultivo en medio TCBS; se aprecia el crecimiento de colonias, de color amarillo.

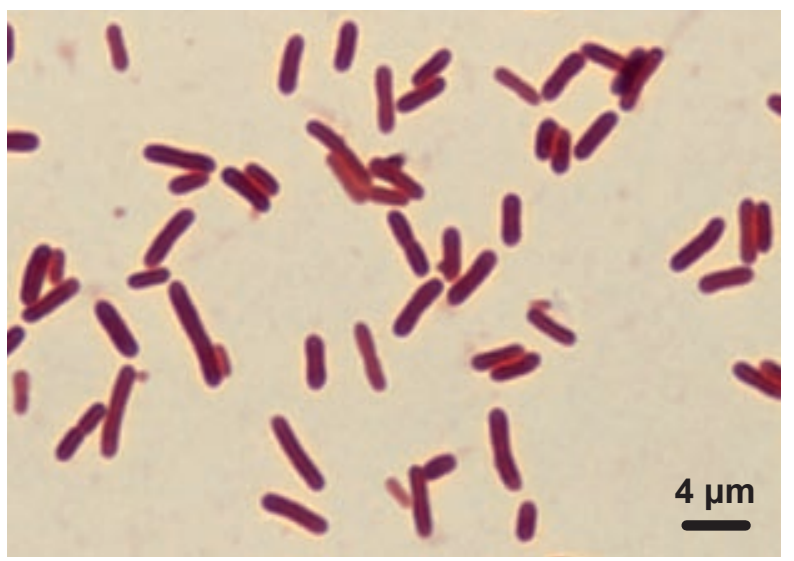

Figura 4. Vibrio parahaemolyticus, agente causal de diarrea, en frotis de cultivo puro, con la tinción de Gram. Se visualizan bacilos Gram negativos.

1 Médico Patólogo Clínico, Servicio de Microbiología, Instituto Nacional de Salud del Niño, Instituto de Medicina Tropical “Daniel A. Carrión”, Universidad Nacional Mayor de San Marcos, Lima, Perú. 


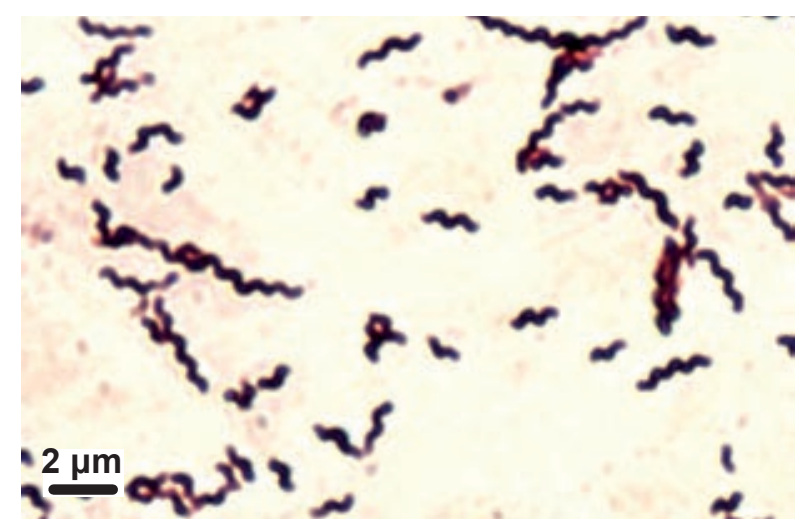

Figura 5. Campylobacter jejuni, agente de diarreas y factor asociado con el síndrome de Guillain-Barré. Frotis de cultivo puro con la tinción de Vago modificada. Se observan bacilos curvados en forma de C, S, espirilar y con morfología en "vuelo de gaviota".

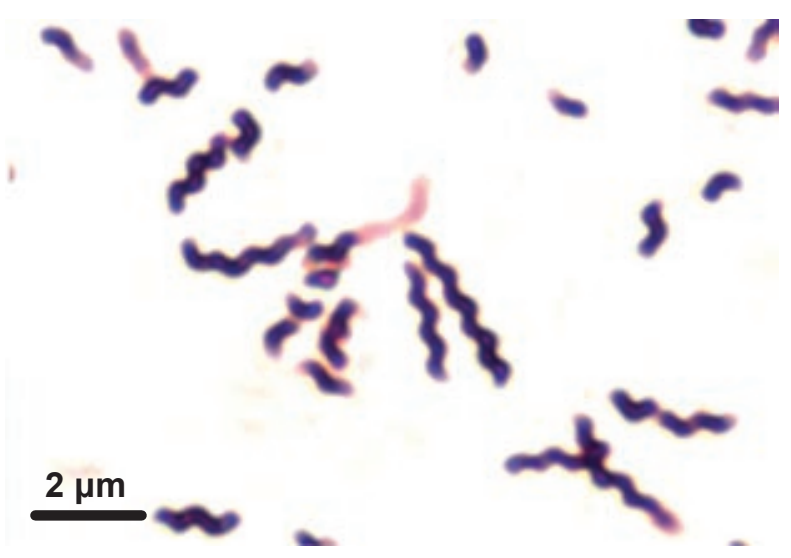

Figura 6. Campylobacter jejuni, en frotis de cultivo puro, con la tinción de Vago modificada. Se observa morfología similar al anterior, a mayor aumento.

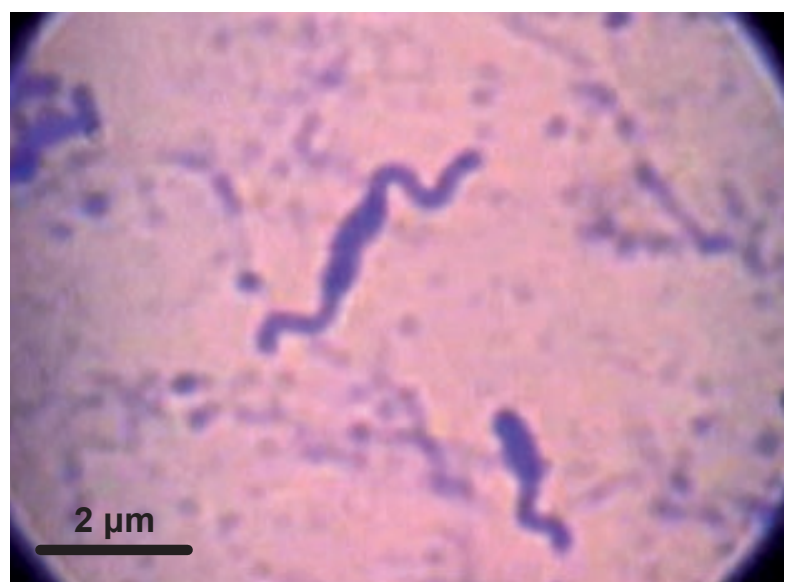

Figura 7. Campylobacter jejuni, se observa al centro con dos flagelos polares y en la parte inferior con un solo flagelo. Tinción de Kodaka.

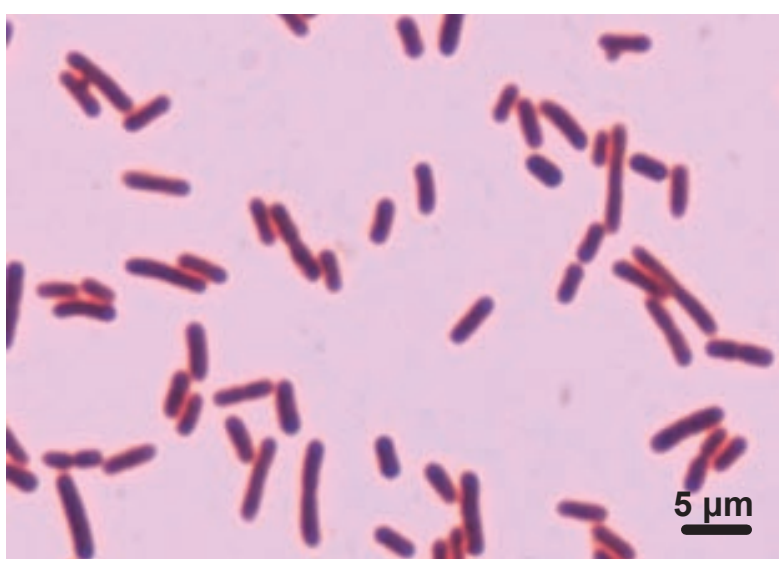

Figura 8. Escherichia coli enterotoxigénica, agente causal de diarrea, en frotis de cultivo puro con tinción de Gram. Se observan bacilos Gram negativos.

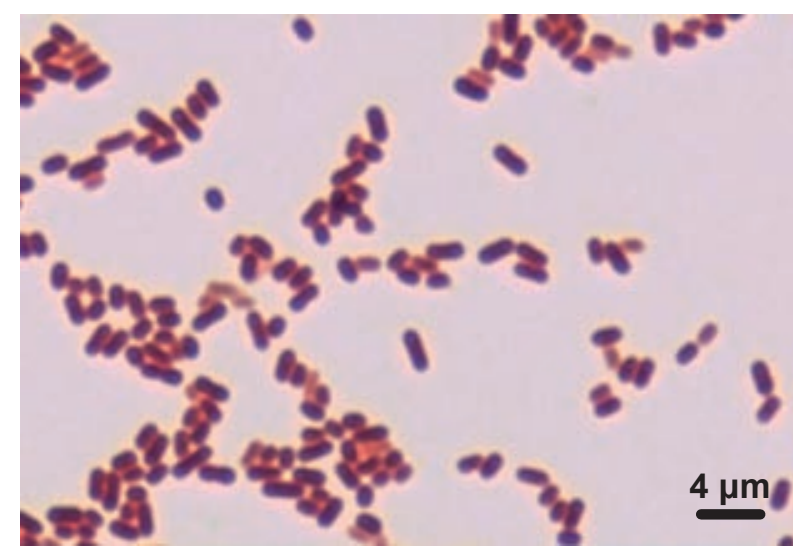

Figura 9. Shigella flexneri, agente causal de diarrea, en frotis de cultivo puro con tinción de Gram. Se observan bacilos pequeños Gram negativos.

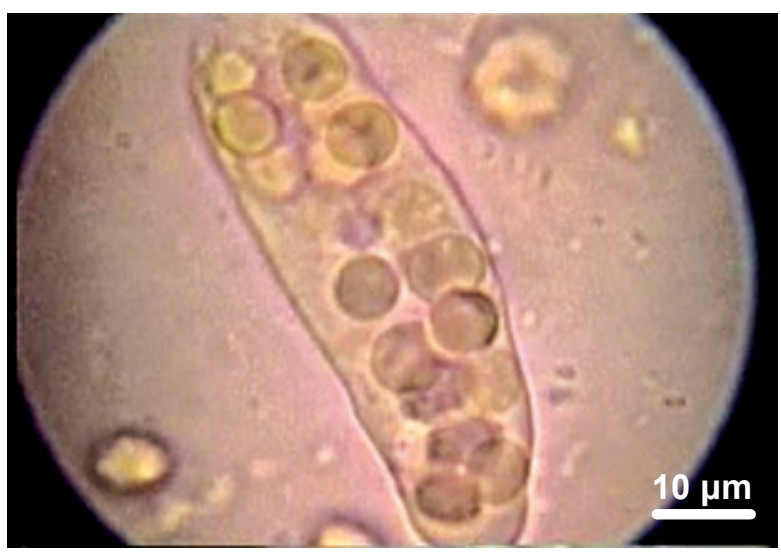

Figura 10. Entamoeba histolytica, agente causal de disentería amebiana, en preparación en fresco; se visualiza un trofozoito con numerosos eritrocitos fagocitados. 


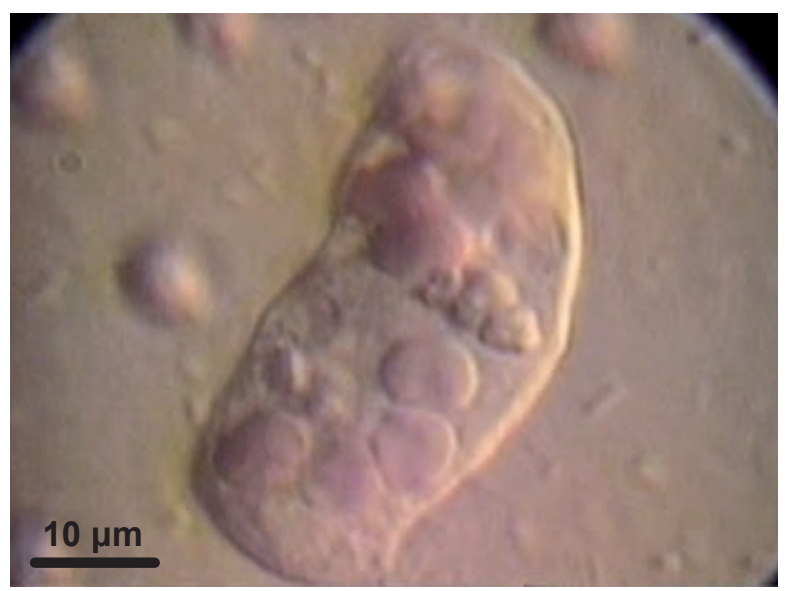

Figura 11. Entamoeba histolytica, preparación en fresco, se aprecia al parásito con eritrocitos fagocitados, en imagen tridimensional.

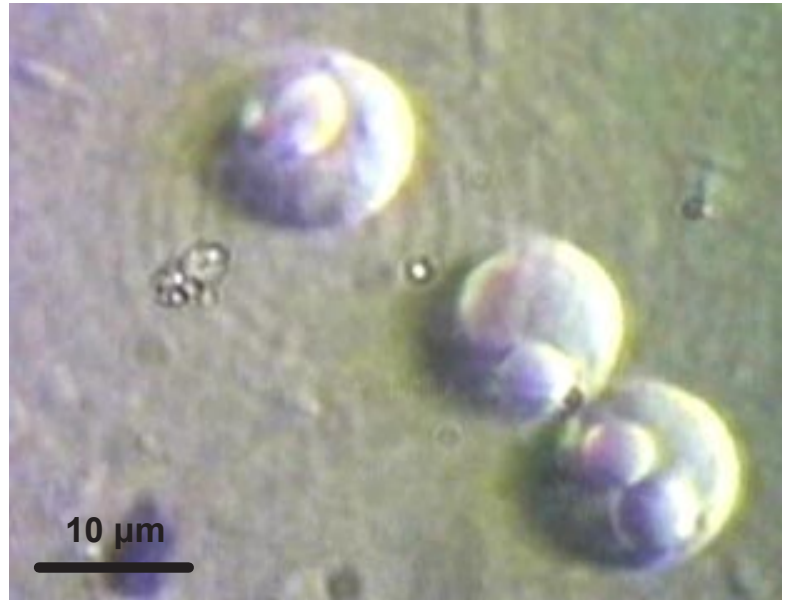

Figura 12. Blastocystis hominis, parásito anaerobio estricto que se encuentra en heces de pacientes con y sin diarrea, en imagen tridimensional de una preparación en fresco, a partir de cultivo.

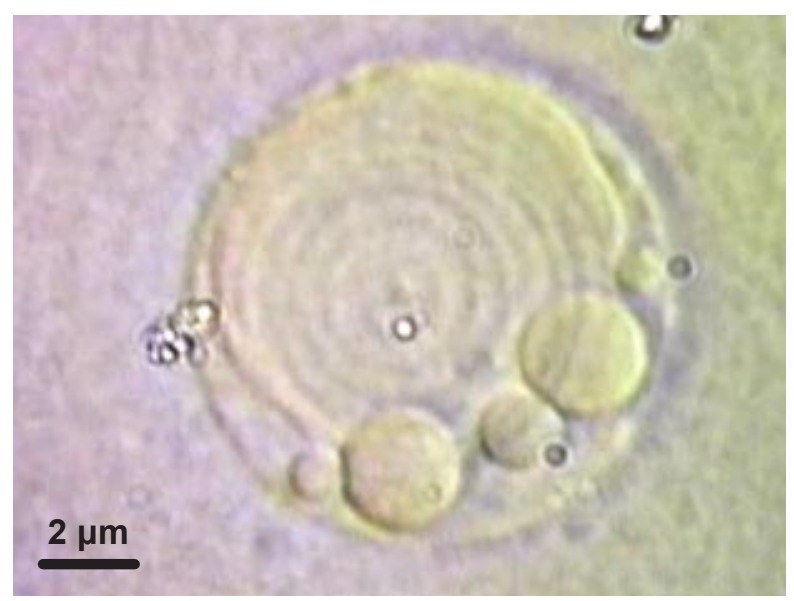

Figura 13. Blastocystis hominis, forma vacuolada o con cuerpo central en imagen tridimensional.

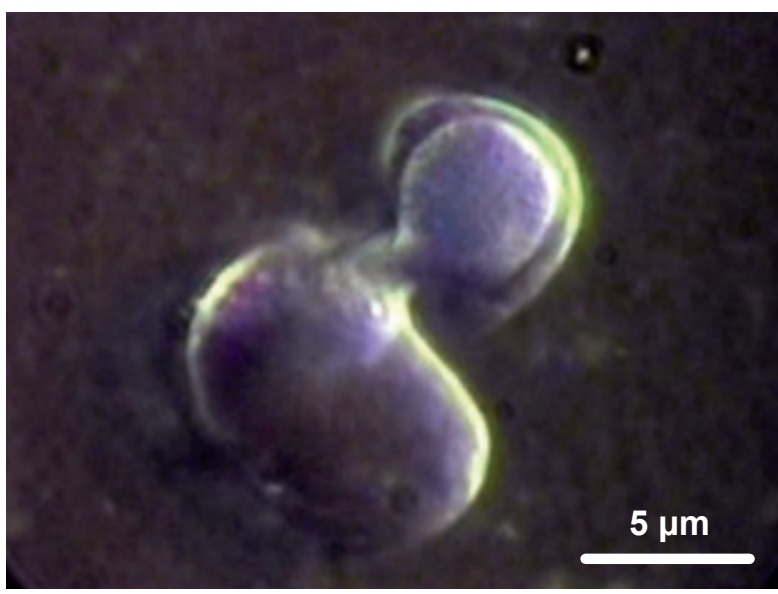

Figura 14. Blastocystis hominis, en plena división por plasmotomía, imagen tridimensional.

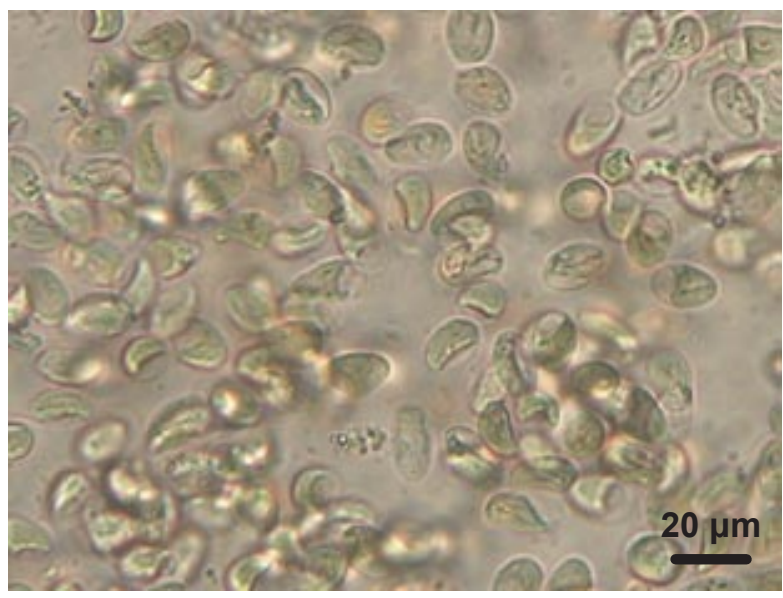

Figura 15. Giardia intestinalis (Giardia lamblia), abundantes trofozoítos en muestra fecal de un paciente con diarrea. Examen directo de una preparación en fresco. (Cortesía del Dr. Alfredo Guillén)

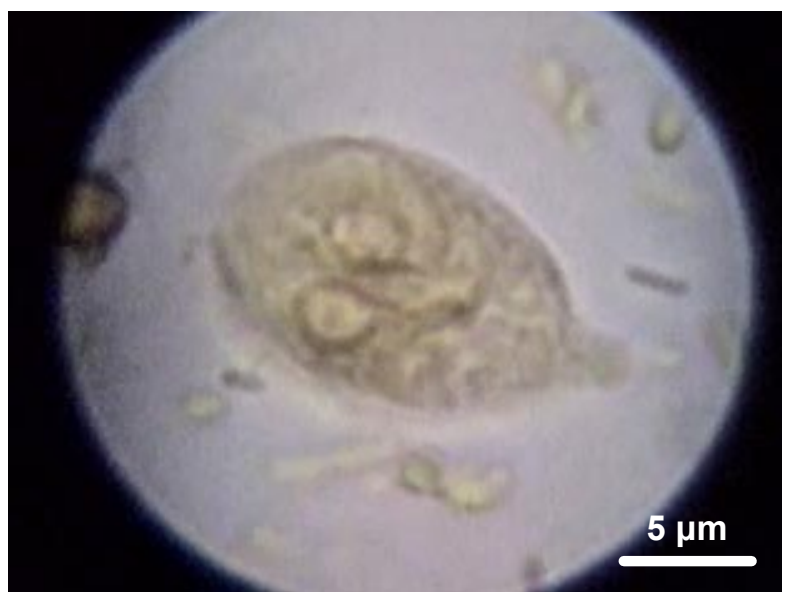

Figura 16. Giardia intestinalis, trofozoíto en preparado en fresco con lugol. 


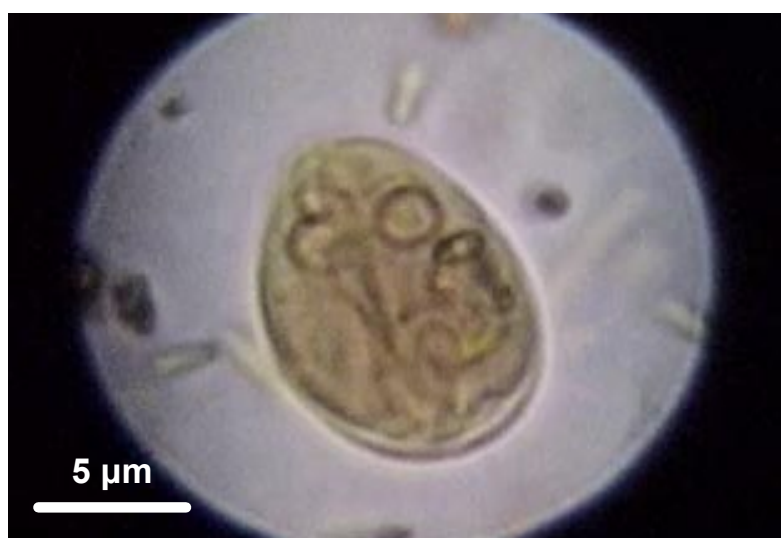

Figura 17. Giardia intestinalis, quiste en preparado en fresco con lugol.

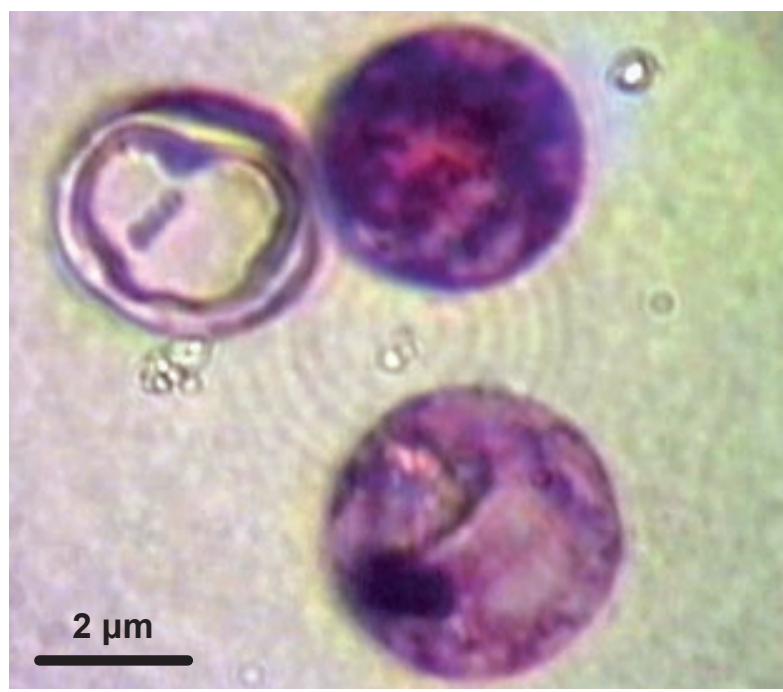

Figura 18. Cryptosporidium parvum, ooquistes en frotis de muestra de heces de un paciente con VIH. Teñido con Kinyoun.

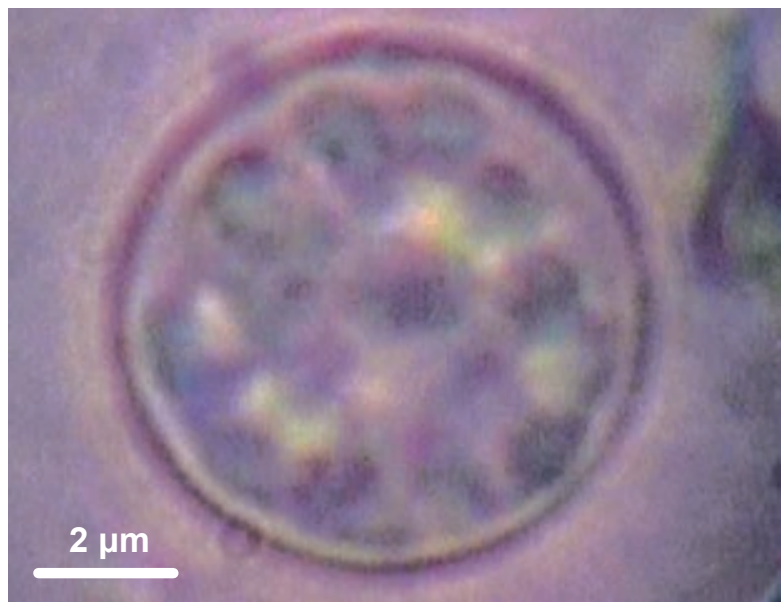

Figura 19. Cyclospora cayetanensis, ooquiste en muestra de heces de un paciente con VIH. Preparación en fresco.

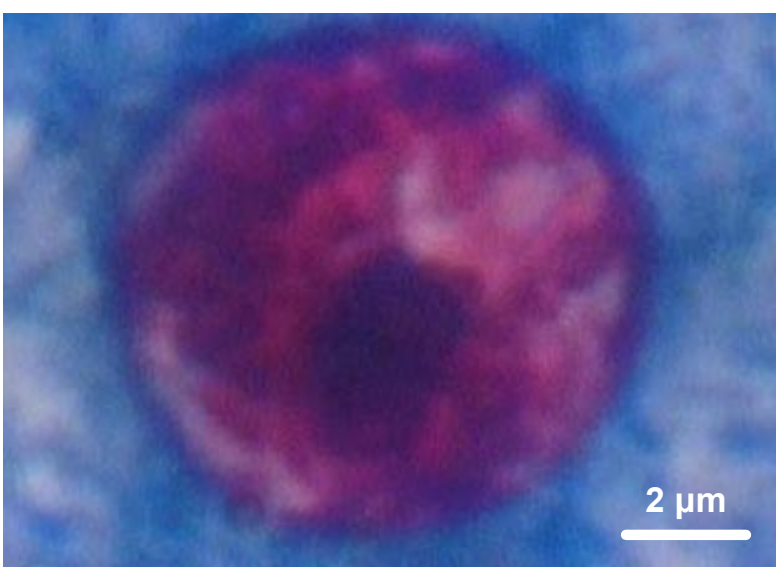

Figura 20. Cyclospora cayetanensis, ooquiste en muestra de heces, de un paciente con VIH. Tinción de Kinyoun.

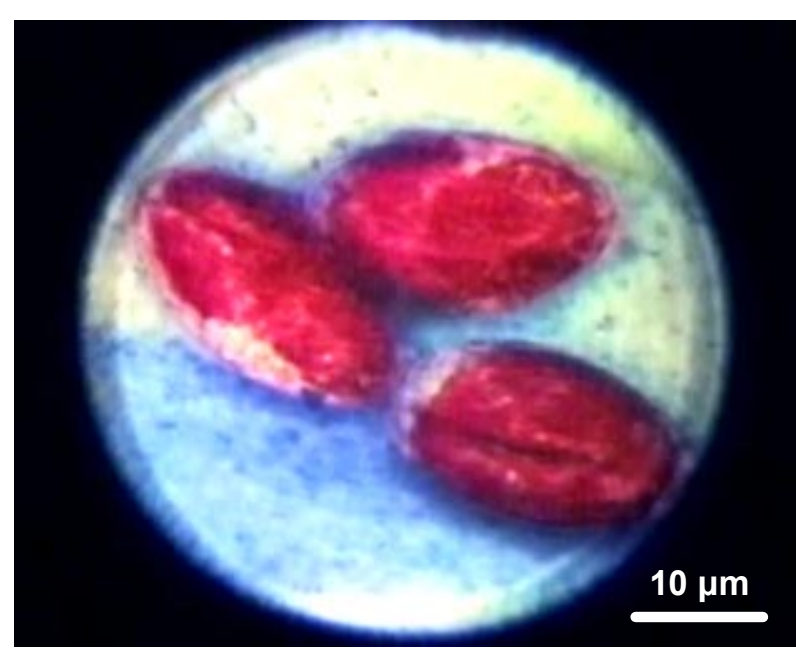

Figura 21. Cystoisospora belli ( Isospora belli), ooquistes en muestra de heces de un niño con VIH. Teñido con Kinyoun.

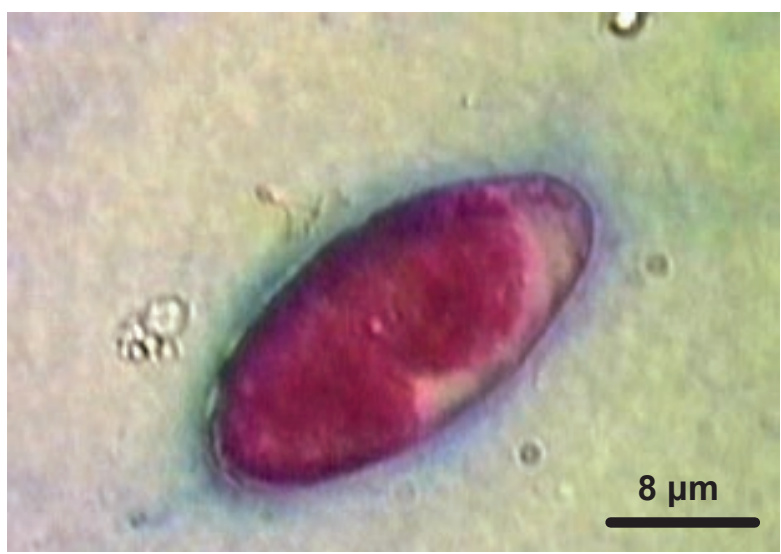

Figura 22. Cystoisospora belli, ooquiste en muestra de heces de un niño con VIH. Teñido con Kinyoun, a mayor aumento.

Correspondencia: Rito Zerpa Larrauri.

Correo electrónico: rzerpa43@yahoo.com 